\title{
Evaluation of genotypic and phenotypic methods for differentiation of the members of the Anginosus group streptococci
}

\author{
P. H. Summanen • M.-C. Rowlinson • J. Wooton • \\ S. M. Finegold
}

Received: 20 March 2009 / Accepted: 10 May 2009/Published online: 4 June 2009

(C) The Author(s) 2009. This article is published with open access at Springerlink.com

\begin{abstract}
The terminology and classification of the Anginosus group streptococci has been inconsistent. We tested the utility of $16 \mathrm{~S}$ rRNA gene and tuf gene sequencing and conventional biochemical tests for the reliable differentiation of the Anginosus group streptococci. Biochemical testing included Rapid ID 32 Strep, API Strep, Fluo-Card Milleri, Wee-tabs, and Lancefield antigen typing. Altogether, 61 Anginosus group isolates from skin and soft tissue infections and four reference strains were included. Our results showed a good agreement between 16S rRNA gene and tuf gene sequencing. Using the full sequence was less discriminatory than using the first part of the 16S rRNA gene. The three species could not be separated with the API 20 Strep test.
\end{abstract}

P. H. Summanen • M.-C. Rowlinson · J. Wooton

Research Service, Veterans Affair Medical Center

West Los Angeles,

Los Angeles, CA, USA

S. M. Finegold

Infectious Diseases Section, Veterans Affair

Medical Center West Los Angeles,

Los Angeles, CA, USA

S. M. Finegold

Department of Medicine, University of California

at Los Angeles School of Medicine,

Los Angeles, CA, USA

S. M. Finegold

Department of Microbiology,

Immunology and Molecular Genetics,

University of California at Los Angeles School of Medicine,

Los Angeles, CA, USA

\section{P. H. Summanen $(\square)$}

Anaerobe Laboratory, VA Wadsworth Medical Center, Building 304, Room E3-237, 11301 Wilshire Boulevard,

Los Angeles, CA 90073, USA

e-mail: carlsonph@aol.com
Streptococcus intermedius could be differentiated from the other two species by $\beta$-galactosidase (ONPG) and $\beta-\mathrm{N}$ acetyl-glucosaminidase reactions. Rapid ID 32 Strep $\beta$ glucosidase reaction was useful in separating $S$. anginosus strains from $S$. constellatus. In conclusion, both 16S rRNA gene and tuf gene sequencing can be used for the reliable identification of the Anginosus group streptococci. $S$. intermedius can be readily differentiated from the other two species by phenotypic tests; however, 16S rRNA gene or tuf gene sequencing may be needed for separating some strains of $S$. constellatus from S. anginosus.

\section{Introduction}

The Anginosus group streptococci (AGS) consist of three species, designated Streptococcus anginosus, Streptococcus constellatus, and Streptococcus intermedius [1,2]. Clinical review and our studies have shown that, while the AGS are found as normal flora in humans, these bacteria are pathogens recognized for their role in pyogenic infections and are strongly associated with abscess formation [3-5]. In a recent study of 400 traumatic and surgical wound infections, we found that species of the Anginosus group were the predominant streptococci recovered; 71 AGS strains were isolated from 60 specimens [6]. The AGS has been described as a heterogenous group, and the terminology and classification of the AGS has always been a source of confusion [7]. An identification scheme proposed by Whiley et al. is considered to be a standard for phenotypic identification of the AGS [1,8]. The 16S rRNA gene sequencing and commercial identification kits commonly used to identify bacteria have been inconsistent in identifying the AGS [7, 9-13]. As a result, AGS strains may often be reported out in the clinical microbiology laboratory 
as 'viridans streptococci.' Picard et al. described a polymerase chain reaction (PCR)-based assay targeting the tuf gene encoding elongation factor $\mathrm{Tu}$ for the specific detection of streptococcal sequences [14]. However, only a few AGS strains were included [14]. We tested the utility of tuf gene sequencing identification and a battery of biochemical tests for the identification of AGS strains to the species level using 16S rRNA gene sequencing as a reference method. Biochemical testing included Rapid ID 32 Strep, API Strep, Fluo-Card Milleri, Wee-tabs, and Lancefield antigen typing.

\section{Methods}

Strains and growth conditions

Sixty-one strains isolated at the VA Wadsworth Medical Center from patients at Olive View-UCLA Medical Center were included. The reference strains for $S$. anginosus (ATCC $33397^{\mathrm{T}}$ ), S. constellatus (ATCC $27823^{\mathrm{T}}$ and ATCC 24889), and S. intermedius (ATCC $27335^{\mathrm{T}}$ ) were included in the biochemical and molecular characterization. Strains were maintained at $-70^{\circ} \mathrm{C}$ in double-strength skim milk before characterization. The strains were grown at $37^{\circ} \mathrm{C}$ on trypticase soy blood agar (TSA, Becton Dickinson Microbiology Systems, Sparks, MD) under microaerophilic conditions $\left(5 \% \mathrm{CO}_{2}\right)$. All testing was done with 24 to 48 -h-old pure cultures.

\section{Genotypic testing}

Genomic DNA was extracted and purified from bacterial cells in the mid-logarithmic growth phase by using a QIAamp DNA Mini Kit (Qiagen, Inc., Chatsworth, CA). The 16S rRNA gene fragments were amplified by standard methods. Two subregions of the 16S rRNA gene were amplified by using two pairs of primers. The first part of the 16S rRNA gene was defined as an approximately 800 -bp region between primers $8 \mathrm{UA}\left(5^{\prime}-\right.$ AGAGTTTGATCCTGGCTCAG-3') and 907B (5'CCGTCAATTCMTTTAGTTT- $3^{\prime}$ ). The second part of the 16S rRNA gene, defined as approximately 700-bp sequences between primers 774A (5'-GTAGTCCACG CTGTAAACGATG-3') and 1485B (5'-TACGGTTACCT TGTTACGAC-3'), was sequenced to obtain the complete 16S rRNA gene sequence on 22 strains (eight $S$. anginosus, nine $S$. constellatus, and five $S$. intermedius). PCR was performed for 35 cycles of $30 \mathrm{~s}$ at $95^{\circ} \mathrm{C}, 30 \mathrm{~s}$ at $45^{\circ} \mathrm{C}$, and $1 \mathrm{~min}$ at $72^{\circ} \mathrm{C}$, with a final extension at $72^{\circ} \mathrm{C}$ for $5 \mathrm{~min}$. The tuf gene fragments were amplified with universal primers Tseq271 (5'-AAYATGATIACIGGIG CIGCICARATGG-3') and Tseq1138 (5'-CCIACIGTICK
ICCRCCYTCRCG-3') to obtain an approximately 760 -bp portion of the gene. The PCR conditions were as follows: $95^{\circ} \mathrm{C}$ for $3 \mathrm{~min} ; 35$ cycles of $95^{\circ} \mathrm{C}$ for $30 \mathrm{~s}, 55^{\circ} \mathrm{C}$ for $1 \mathrm{~min}$, and $72^{\circ} \mathrm{C}$ for $1 \mathrm{~min}$; and a final extension of $72^{\circ} \mathrm{C}$ for $5 \mathrm{~min}$. The PCR products were excised from a $1 \%$ agarose gel after electrophoresis and purified using a QIAquick Gel Extraction Kit (Qiagen). The purified PCR products were sequenced directly with BigDye Terminator Cycle Sequencing Kits (Biotech Diagnostics, Tustin, CA) on an ABI 3100 Avant Genetic System (Applied Biosystems, Foster City, CA). The sequencing data was analyzed by comparison of the consensus sequences with GenBank sequences by using the Ribosomal Database Project (RDP-II) and the Basic Local Alignment Search Tool software (BLAST), and the percentage similarity to other sequences was determined. Closely related sequences were retrieved from GenBank and were aligned with the newly determined sequences by using the program CLUSTAL W.

\section{Phenotypic testing}

The Lancefield antigen was detected using the Streptex* Lancefield Streptococci Latex Test (Remel, Lenexa, KS) according to the manufacturer's instructions. Preformed enzyme profiles were characterized by API Strep and Rapid ID Strep (bioMérieux, Marcy l'Etoile, France) according to the manufacturer's instructions using API Suspension Medium (bioMérieux) to prepare inocula. Fluo-Card Milleri tests were performed according to the manufacturer's instructions (Key Scientific Products Co., Stamford, TX). Additionally, Wee-tabs $\alpha$-glucosidase, $\beta$ fucosidase, $\beta$-glucosidase, $\beta$-N-acetyl-glucosaminidase ( $\beta$-NAG), esculin, and ONPG (Key Scientific Products Co.), were included in the characterization. TSA blood agar was used for the detection of hemolysis.

\section{Results}

Strains

Next to Staphylococcus aureus, the AGS were the second most common isolates ( 71 isolates from 60 specimens; 31 S. anginosus, 28 S. constellatus, 11 S. intermedius, and one AGS) found during our comprehensive microbiological evaluation of 400 skin and soft tissue infections. Of the 61 strains included in this study, 29 were S. anginosus (sources: perirectal and torso below the diaphragm [17], lower extremity [4], upper extremity [7], and breast [1]), $21 S$. constellatus (perirectal and torso below the diaphragm [11], lower extremity [3], upper extremity [1], and head and neck [6]), and 11 S. intermedius (perirectal and 
torso below the diaphragm [3], upper extremity [6], and head and neck [2]).

\section{Genotypic testing}

The reference strains' 16S rRNA gene sequences matched those deposited in GenBank with 100\% sequence similarity. Similarly, for all of the clinical strains tested, the 16S rRNA gene sequencing identified the correct species as the first choice with $\geq 98 \%$ sequence similarity to the reference strain sequences (Table 1). Twenty-eight of $29(97 \%)$ of $S$. anginosus were named with $\leq 2 \%$ distance from the next named species using the first part of the 16S rRNA gene, whereas only $4 / 8(50 \%) S$. anginosus tested were named with $\leq 2 \%$ distance using the full $16 \mathrm{~S}$ rRNA gene. Similarly, $6 / 21$ (29\%) of $S$. constellatus and 10/11 (91\%) of $S$. intermedius were named with $\leq 2 \%$ distance from the next named species using the first part of the 16S rRNA gene, but only $1 / 9(11 \%)$ and $2 / 5(40 \%)$, respectively, using the full 16S rRNA gene. Further, the full 16S rRNA gene sequence did not give discriminatory results for three $S$. constellatus and two $S$. intermedius strains. For all of the strains tested, the $t u f$ gene sequencing identified the correct species at $100-98 \%$ sequence similarity to the reference species (Table 1). Nine of 29 (31\%) of S. anginosus, 20/21 $(95 \%)$ of S. constellatus, and $11 / 11(100 \%)$ of $S$. intermedius were named with $\leq 2 \%$ distance from the next named species by tuf gene sequencing.

Phenotypic testing

Of the $29 S$. anginosus strains, two were $\beta$-hemolytic and the rest were $\alpha$-hemolytic. Most $S$. anginosus strains possessed a Lancefield antigen: 16 were Lancefield group F, six Lancefield group $C$, three Lancefield group $\mathrm{G}$, and four were non-typable. Of the $21 \mathrm{~S}$. constellatus strains, seven were $\beta$-hemolytic and the rest were $\alpha$-hemolytic; eight strains possessed Lancefield group $\mathrm{F}$ antigen, whereas the rest had no antigen. All $11 \mathrm{~S}$. intermedius isolates were $\alpha$-hemolytic, three belonged to Lancefield group $\mathrm{F}$, and eight had no antigen. The key phenotypic characteristics obtained by the Rapid ID 32 Strep, API Strep, and Wee-tab systems are given in Table 2. The other results are given below. All strains were positive for arginine dihydrolase, alkaline phosphatase, saccharose, Voges-Proskauer, alanylphenylalanyl-proline arylamidase, and maltose, and all strains were negative for $\beta$-glucuronidase, ribose, mannitol, sorbitol, arabinose, arabitol, cyclodextrin, glycogen, melezitose, and urease using the Rapid ID 32 Strep test. In addition, $S$. constellatus and $S$. intermedius were negative for $\alpha$-galactosidase, raffinose, pyroglutamic acid arylamidase, hippurate, melibiose, and tagatose, whereas $S$. anginosus reactions were variable. All of the strains were positive for Voges-Proskauer, alkaline phosphatase, leucine aminopeptidase, arginine dihydrolase, and trehalose acidification, and variable for lactose and amidon acidification using the API Strep system. At $24 \mathrm{~h}, \mathrm{~S}$. constellatus esculin was variable. In addition, $S$. anginosus were occasionally positive for $\alpha$-galactosidase and ribose, arabinose, mannitol, inulin, and raffinose acidification. Wee-tabs $\alpha$ glucosidase, $\beta$-glucosidase, and esculin reactions were variable with all of the strains tested.

Using the Fluo-Card Milleri, all S. intermedius strains were $\beta$-fucosidase-positive and, thus, correctly identified (Table 3). Only $45 \%$ of the $S$. anginosus strains were correctly identified as $S$. anginosus; $55 \%$ of the $S$.

Table 1 16S rRNA and tuf gene sequencing identification of the Streptococcus anginosus group

$\%$ sequence similarity ${ }^{1}$ (next named species)

16S rRNA sequencing ID tuf gene ID

S. anginosus

ATCC $33397^{\mathrm{T}}$

Clinical isolates $(n=29)$

$100 \%$ S. anginosus $(96 \%$ S. intermedius)

$100-98 \%$ S. anginosus (96-94\%

S. intermedius/constellatus)

S. constellatus

ATCC $27823^{\mathrm{T}}$

ATCC 24889

Clinical isolates $(n=21)$

$100 \%$ S. constellatus $(98 \%$ S. intermedius)

$100 \%$ S. constellatus ( $98 \%$ S. intermedius)

$100-99 \%$ S. constellatus (98-97\% S. intermedius)

S. intermedius

ATCC $27335^{\mathrm{T}}$

Clinical isolates $(n=11)$
$100 \%$ S. intermedius ( $98 \%$ S. constellatus/anginosus)

$100 \%$ S. intermedius ( $98 \%$ S. constellatus)
$100 \%$ S. anginosus $(97 \%$ S. constellatus $)$

99-98\% S. anginosus $(98-97 \%$

S. intermedius/constellatus)

99\% S. constellatus (97\% S. intermedius)

$100 \%$ S. constellatus $(98 \%$ S. intermedius)

$100-99 \%$ S. constellatus (98-97\%

$S$. anginosus/intermedius)

$100 \%$ S. intermedius ( $96 \%$ S. constellatus/anginosus) 99-98\% S. intermedius (97-96\%

S. anginosus/constellatus)

\footnotetext{
${ }^{1}$ For all of the strains tested, both the $16 \mathrm{~S}$ rRNA gene sequencing and the tuf gene sequencing identified the correct species as the first choice
} 
Table 2 Key differential phenotypic characteristics of the $S$. anginosus group ${ }^{1}$

\begin{tabular}{|c|c|c|c|c|c|c|c|}
\hline & \multicolumn{2}{|l|}{ S. anginosus } & \multicolumn{3}{|l|}{ S. constellatus } & \multicolumn{2}{|l|}{ S. intermedius } \\
\hline & ATCC 33397 & $\begin{array}{l}\text { Clinical strains, } \\
n=29\end{array}$ & ATCC 27823 & ATCC 24889 & $\begin{array}{l}\text { Clinical strains, } \\
n=21\end{array}$ & ATCC 27335 & $\begin{array}{l}\text { Clinical strains, } \\
n=11\end{array}$ \\
\hline Lancefield antigen & G & $\mathrm{F}, \mathrm{C}, \mathrm{G}, \mathrm{N}$ & $\mathrm{N}$ & $\mathrm{N}$ & $\mathrm{N}, \mathrm{F}$ & $\mathrm{N}$ & $\mathrm{N}, \mathrm{F}$ \\
\hline Hemolysis & $\beta$ & $\alpha, \beta$ & $\alpha$ & $\alpha$ & $\alpha, \beta$ & $\alpha$ & $\alpha$ \\
\hline \multicolumn{8}{|l|}{ Rapid ID 32 STREP } \\
\hline$\beta$-glucosidase & + & + & - & - & $-^{+}$ & + & + \\
\hline$\beta$-galactosidase & - & - & - & - & - & + & + \\
\hline $\begin{array}{l}\beta-\mathrm{N} \text {-acetyl- } \\
\text { glucosaminidase }\end{array}$ & - & - & - & - & - & + & + \\
\hline Pullulan & + & $+^{-}$ & - & - & - & + & $\mathrm{v}$ \\
\hline$\beta$-mannosidase & + & $\mathrm{v}$ & - & - & - & + & + \\
\hline \multicolumn{8}{|l|}{ API Strep } \\
\hline Esculin (4 h) & + & + & - & - & - & - & $\mathrm{v}$ \\
\hline \multicolumn{8}{|l|}{ Wee-tabs } \\
\hline$\beta$-fucosidase & - & - & - & - & - & + & + \\
\hline $\begin{array}{l}\beta \text {-N-acetyl- } \\
\text { glucosaminidase }\end{array}$ & - & - & - & - & - & + & + \\
\hline ONPG & - & - & - & - & - & + & + \\
\hline
\end{tabular}
${ }^{1} \mathrm{~N}=$ no antigen; $+=>90 \%$ of strains are positive $;-=>90 \%$ of strains are negative; $+^{-}=80-90 \%$ of strains are positive; $-^{+}=80-90 \%$ of strains
are negative; $\mathrm{v}=$ variable reaction

anginosus strains were $\beta$-fucosidase-positive (but $\beta$ glucosidase-negative). Fluo-Card Milleri identified $76 \%$ of S. constellatus strains correctly (Table 3 ).

\section{Discussion}

It has been reported that there is an association between clinical sites of infection and the different species of AGS where $S$. anginosus is predominantly associated with gastrointestinal sources, $S$. constellatus with all types of abscesses, and $S$. intermedius with intracerebral abscesses [3, 5, 15-17]. Our study included isolates from a skin and soft tissue infection study only, but some general trends can be observed from our results: $S$. anginosus were predom- inantly isolated from below the diaphragm specimens, whereas $S$. intermedius were mostly isolated from above the diaphragm specimens. Also, similar to previous reports, all of the isolates from head and neck sources were either $S$. constellatus or S. intermedius [17]. Our results on the distribution of hemolysis and Lancefield group were similar to those previously described (Table 2) [1, 13, 17]. However, none of our $\beta$-hemolytic $S$. constellatus isolates carried the Lancefield group $\mathrm{C}$ antigen associated with $S$. constellatus subsp. pharyngis and the human throat [2].

Our results showed good agreement between the $16 \mathrm{~S}$ rRNA gene sequencing and tuf gene sequencing. However, GenBank has a lot of sequences of poorly characterized (misnamed) species. Therefore, for identification, the $16 \mathrm{~S}$ rRNA gene sequences must be compared only to those of
Table 3 Fluo-Card Milleri identification of the $S$. anginosus group $^{1}$
$1+=>90 \%$ of strains are positive; - $=>90 \%$ of strains are negative; $+^{-}=80-90 \%$ of strains are positive; $-^{+}=80-$ $90 \%$ of strains are negative

${ }^{2}$ Includes reference strain(s)

\begin{tabular}{|c|c|c|c|c|}
\hline \multirow[t]{2}{*}{ 16S ID } & \multicolumn{3}{|c|}{ Fluo-Card reaction } & \multirow[t]{2}{*}{ Fluo-Card ID } \\
\hline & $\beta$-fucosidase & $\beta$-glucosidase & $\alpha$-glucosidase & \\
\hline \multicolumn{5}{|c|}{ S. anginosus } \\
\hline$(n=14)^{2}$ & - & + & $-^{+}$ & S. anginosus $(45 \%)$ \\
\hline$(n=16)$ & + & - & + & S. intermedius $(55 \%)$ \\
\hline \multicolumn{5}{|c|}{ S. constellatus } \\
\hline$(n=18)^{2}$ & - & - & $+^{-}$ & S. constellatus $(76 \%)$ \\
\hline$(n=5)$ & - & + & $-^{+}$ & S. anginosus $(24 \%)$ \\
\hline \multicolumn{5}{|c|}{ S. intermedius } \\
\hline$(n=11)^{2}$ & + & + & $+^{-}$ & S. intermedius $(100 \%)$ \\
\hline
\end{tabular}


well characterized reference strains in GenBank: accession numbers AB 355609 and $\mathrm{AF} 10467$ for S. anginosus; $\mathrm{AB}$ 355605 and AF 104676 for S. constellatus; and AF104671 for $S$. intermedius. Furthermore, the last part of the $16 \mathrm{~S}$ rRNA gene seems to be less discriminatory, and, therefore, using the first part of the 16S rRNA gene ( 700-800 bp) gave better results than the full 16S rRNA gene sequence $(\sim 1,400 \mathrm{bp})$. Picard et al. performed an extensive sequence analysis of 28 streptococcal species and showed that tuf gene sequencing generally resulted in better discrimination of the species than 16S rRNA gene sequencing [14]. More specifically, they observed that tuf gene sequencing performed well in discriminating the AGS; however, their study included only the type strains of the three species and three $S$. anginosus clinical strains [14]. Our results expand this observation: $t u f$ gene sequencing correctly identified all of the reference strains and 61 clinical isolates included in the present study.

We studied the utility of Rapid ID 32 Strep, API Strep, Fluo-Card Milleri, and Wee-tabs for the identification of the AGS. Our biochemical test results were generally in agreement with those reported earlier $[1,7,13]$. The Rapid ID 32 Strep proved to be most useful in separating the three AGS species (Table 2). S. intermedius could readily be differentiated from the other two species by Rapid ID 32 Strep $\beta$-galactosidase and $\beta$-NAG reactions; this result is unlike that reported by Limia et al. 1 [11], who found that only $57 \%$ of the $S$. intermedius strains were correctly identified by the Rapid ID 32 Strep test. Three of the $S$. anginosus strains tested gave red-orange (positive) reaction in the Rapid ID 32 Strep resorufin- $\beta$ D-galactopyranoside test (well 1.2), whereas the 2-naphthyl- $\beta \mathrm{D}$-galactopyranoside test (well 0.2) yielded a pale purple color, which would be interpreted as negative. Wee-tabs $\beta$-fucosidase, $\beta$-NAG, and ONPG readily separated $S$. intermedius (all positive) from the other two species (all negative). The Rapid ID 32 Strep $\beta$-glucosidase reaction could be used to separate $S$. anginosus strains from $S$. constellatus; all $\beta$-glucosidasenegative strains were $S$. constellatus. Our Fluo-Card Milleri results are not in complete agreement with previous reports $[10,13]$. All $S$. intermedius strains were correctly identified; however, $55 \%$ of the $S$. anginosus strains also showed $\beta$-fucosidase activity with this method, and would, therefore, be identified as $S$. intermedius by Fluo-Card (Table 3). Unlike $S$. intermedius, all $\beta$-fucosidase-positive $S$. anginosus strains were $\beta$-glucosidase-negative, which could be used as a distinguishing characteristic between these two species. Our results also indicate that $24 \%$ of $S$. constellatus are $\beta$-glucosidase-positive in the Fluo-Card Milleri test and, therefore, could be misidentified.

In conclusion, both $16 \mathrm{~S}$ rRNA gene and tuf gene sequencing can be used for the reliable identification of the AGS. If using $16 \mathrm{~S}$ rRNA gene sequencing for the identification of the AGS, care must be taken to compare the sequences only to those of well characterized strains in GenBank. S. intermedius could readily be differentiated from the other two species by biochemical tests, such as the Rapid ID 32 Strep and Wee-tab $\beta-N A G$ and ONPG tests. Biochemical tests, such as the Rapid ID 32 Strep $\beta$ glucosidase reaction, are useful in the differentiation of $S$. anginosus from S. constellatus; however, in some cases, $16 \mathrm{~S}$ rRNA gene or tuf gene sequencing is needed to separate these two species.

Acknowledgments This work has been supported by DOD grant no. W81XWH-0510134 and by VA Merit Review funds.

Open Access This article is distributed under the terms of the Creative Commons Attribution Noncommercial License which permits any noncommercial use, distribution, and reproduction in any medium, provided the original author(s) and source are credited.

\section{References}

1. Whiley RA, Fraser H, Hardie JM, Beighton D (1990) Phenotypic differentiation of Streptococcus intermedius, Streptococcus constellatus, and Streptococcus anginosus strains within the "Streptococcus milleri group." J Clin Microbiol 28:1497-1501

2. Whiley RA, Hall LM, Hardie JM, Beighton D (1999) A study of small-colony, beta-haemolytic, Lancefield group C streptococci within the anginosus group: description of Streptococcus constellatus subsp. pharyngis subsp. nov., associated with the human throat and pharyngitis. Int J Syst Bacteriol 49(Pt 4):1443-1449

3. Whiley RA, Beighton D, Winstanley TG, Fraser HY, Hardie JM (1992) Streptococcus intermedius, Streptococcus constellatus, and Streptococcus anginosus (the Streptococcus milleri group): association with different body sites and clinical infections. J Clin Microbiol 30:243-244

4. Whiley RA, Freemantle L, Beighton D, Radford JR, Hardie JM, Tillotsen G (1993) Isolation, identification and prevalence of Streptococcus anginosus, S. intermedius and S. constellatus from the human mouth. Microb Ecol Health Dis 6:285-291

5. Clarridge JE III, Attorri S, Musher DM, Hebert J, Dunbar S (2001) Streptococcus intermedius, Streptococcus constellatus, and Streptococcus anginosus ("Streptococcus milleri group") are of different clinical Importance and are not equally associated with abscess. Clin Infect Dis 32(10):1511-1515. doi:10.1086/320163

6. Finegold SM, Talan D, Hiyama S, Rowlinson M-C, Summanen P, Molitoris D et al (2008) Analysis of 400 surgical and traumatic wound infections and closed abscesses by molecular techniques for development of a real-time PCR procedure. In: Proceedings of the American Society for Microbiology (ASM) 108th General Meeting, Boston, Massachusetts, June 2008, C-110

7. Facklam R (2002) What happened to the streptococci: overview of taxonomic and nomenclature changes. Clin Microbiol Rev 15 (4):613-630. doi:10.1128/CMR.15.4.613-630.2002

8. Whiley RA, Beighton D (1991) Emended descriptions and recognition of Streptococcus constellatus, Streptococcus intermedius, and Streptococcus anginosus as distinct species. Int J Syst Bacteriol 41:1-5

9. Ahmet Z, Warren M, Houang ET (1995) Species identification of members of the Streptococcus milleri group isolated from the vagina by ID 32 Strep system and differential phenotypic characteristics. J Clin Microbiol 33:1592-1595 
10. Flynn CE, Ruoff KL (1995) Identification of "Streptococcus milleri" group isolates to the species level with a commercially available rapid test system. J Clin Microbiol 33(10):2704-2706

11. Limia A, Alarcón T, Jiménez ML, López-Brea M (2000) Comparison of three methods for identification of Streptococcus milleri group isolates to species level. Eur J Clin Microbiol Infect Dis 19(2):128-131. doi:10.1007/s100960050444

12. Whiley RA, Hall LMC, Hardie JM, Beighton D (1997) Genotypic and phenotypic diversity within Streptococcus anginosus. Int J Syst Bacteriol 47(3):645-650

13. Clarridge JE III, Osting C, Jalali M, Osborne J, Waddington M (1999) Genotypic and phenotypic characterization of "Streptococcus milleri" group isolates from a Veterans Administration hospital population. J Clin Microbiol 37(11):3681-3687

14. Picard FJ, Ke D, Boudreau DK, Boissinot M, Huletsky A, Richard D et al (2004) Use of tuf sequences for genus-specific PCR detection and phylogenetic analysis of 28 streptococcal species. $\mathrm{J}$ Clin Microbiol 42(8):3686-3695. doi:10.1128/JCM.42.8.36863695.2004

15. Piscitelli SC, Shwed J, Schreckenberger P, Danziger LH (1992) Streptococcus milleri group: renewed interest in an elusive pathogen. Eur J Clin Microbiol Infect Dis 11:491-498. doi:10.1007/BF01960802

16. Petti CA, Simmon KE, Bender J, Blaschke A, Webster KA, Conneely MF et al (2008) Culture-negative intracerebral abscesses in children and adolescents from Streptococcus anginosus group infection: a case series. Clin Infect Dis 46(10):1578-1580. doi:10.1086/587655

17. Jacobs JA, Pietersen HG, Stobberingh EE, Soeters PB (1995) Streptococcus anginosus, Streptococcus constellatus and Streptococcus intermedius. Clinical relevance, hemolytic and serologic characteristics. Am J Clin Pathol 104(5):547-553 